\title{
Automation of analytical activities - the way to improve the performance quality of an enterprise. Using the diagnostic chart to assess and improve the financial condition of an enterprise
}

\author{
Rezeda Musaeva ${ }^{1, *}$, Lilya Urazbakhtina ${ }^{1}$, Nina Serkina ${ }^{1}$, Nailya Askarova ${ }^{2}$ and Milyausha Sayfullina ${ }^{2}$ \\ ${ }^{1}$ Associate Professor of the EOP department of the FSBEI HE KSPEU \\ ${ }^{2}$ Kazan Branch, RANEPA
}

\begin{abstract}
The analysis of financial and economic activities is based on financial accounts and forecasting external and internal factors affecting the activities of enterprises. The use of diagnostic diagrams allows complex multidimensional indicators of enterprise activity to be presented in a simple and clear form.
\end{abstract}

\section{Introduction}

Financial management as a science has a complex structure. The analysis of financial and economic activities is based on financial accounts and forecasting external and internal factors affecting the activities of enterprises. The result of the analysis of the enterprise is management. To manage means to foresee, to make decisions, and for this you need to have reliable and objective information.

Information obtained through analytical work is useful for management purposes if they follow such basic principles of analysis as relevance, reliability, materiality, comparability, compatibility, immediacy, timeliness, and others. A financial statement is the information base for analytical calculations and for making management decisions. Financial decisions will be accurate as far as original sources are reliable and objective.
A financial manager is always a key person in an enterprise. He is responsible for setting basic risks of business processes of a financial nature, the expediency of using the decision made by the company's management, and the proposals that are most acceptable in current reality.

So, successful financial management is aimed at the survival of an enterprise in a competitive environment, avoiding bankruptcy and major financial failures, leadership in dealing with competitors, acceptable growth rates of the enterprise's economic potential, growth in production and sales, profit maximization, cost minimization, and ensuring profitable work enterprises.

Every company should have its own analytical service. Analytical work is accompanied by the calculation of a large volume of various quantities and the performance of various types of assessments, groupings, comparisons, etc. The results of calculations require a graphical or a tabular presentation.

* Corresponding author: rezedakbs@mail.ru 


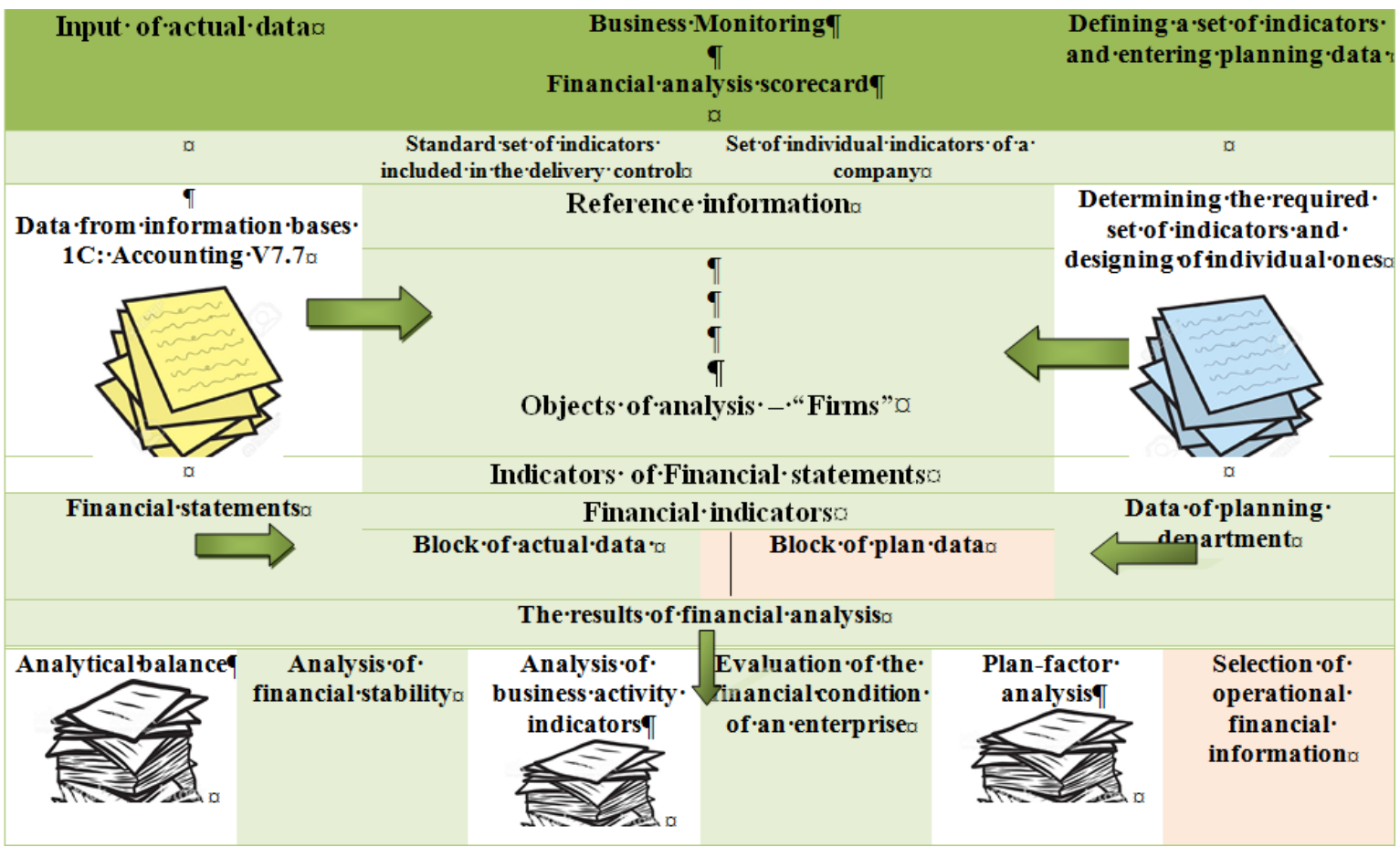

Fig. 1. The block diagram of the configuration "Business Monitoring".

A number of considerations necessitate the use of information technology, the need for timely, accurate and relevant information for expanding future planning, facilitating policy analysis, diversifying and improving administrative operations.[7] Modern information technologies (IT) allow the analyst to formulate and solve the following classes of problems.

An example of the successful creation of a modern information analytical system (IAS) can be the financial analysis and control subsystem "Business Monitoring", which is a product of the " $1 \mathrm{C}$ : Enterprise" program system. The configuration allows, within a single information base, to conduct a financial analysis of any number of enterprises for an arbitrary period of time. An arbitrary number of "projects" can be formed for each enterprise. Figure 1 shows a block diagram of the configuration.

The user of the "Business Monitoring" system can independently create a list of economic indicators which are necessary for the formation of plans of development. The list of indicators for analyzing the activities of an enterprise should be grouped according to their

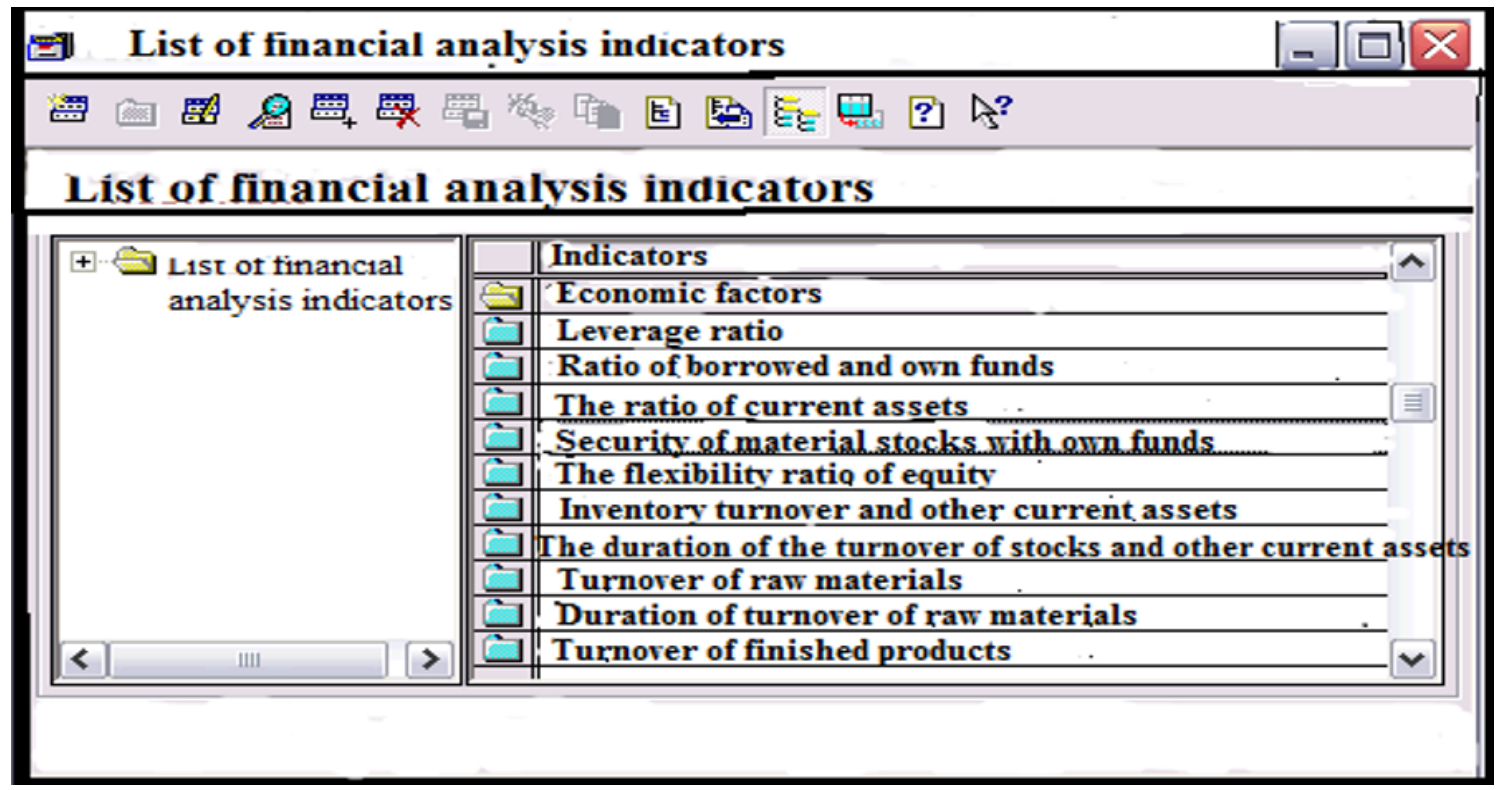

Fig. 2. The example of the list of indicators. 


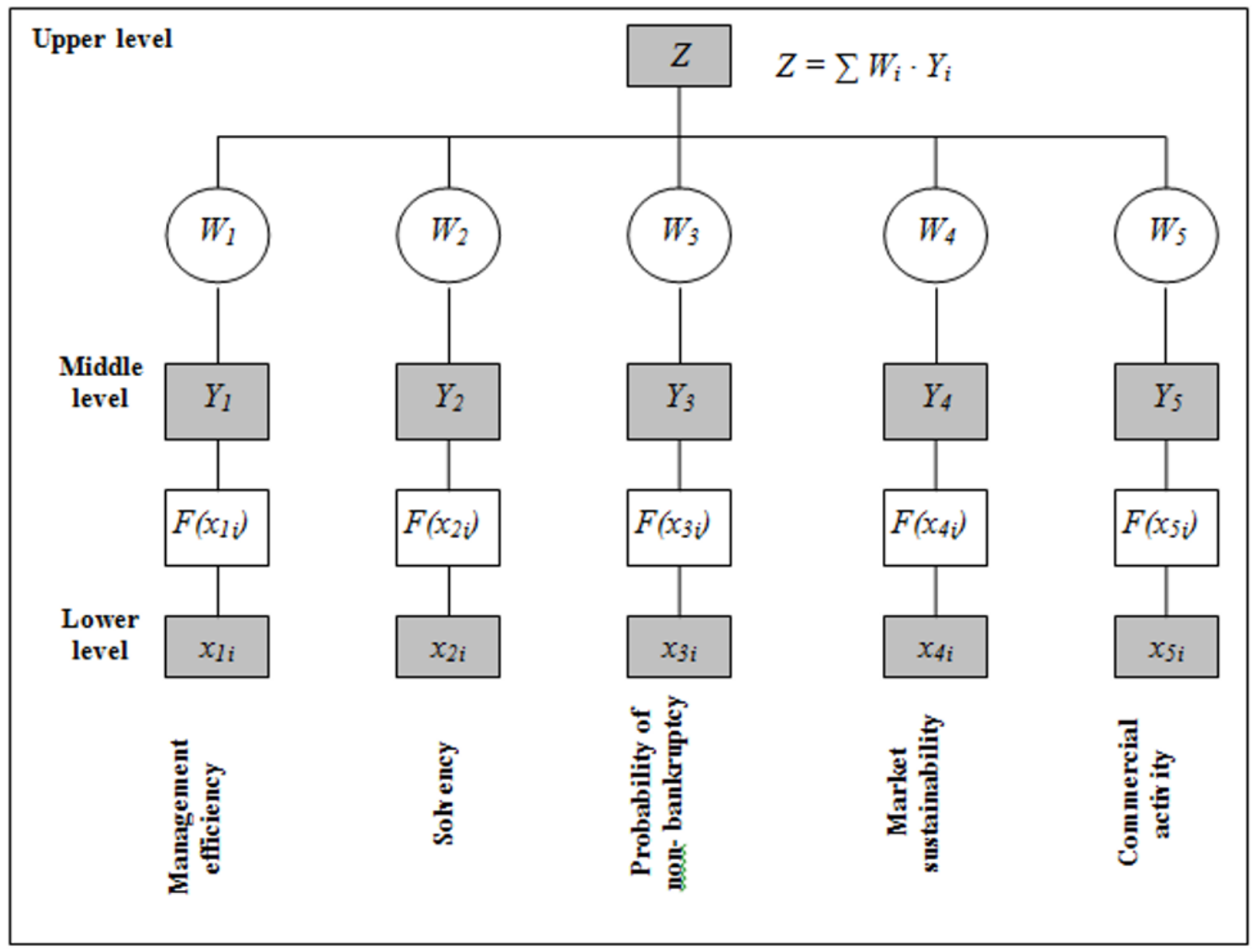

Fig. 3. The tree of indicators of financial condition.

economic content (Fig. 2).

The system provides the ability to store regulatory values of financial indicators both within the industrial and within the firm ones. A fixed standard value or a range of values from and to can be set to each indicator.

The development of the IAS follows the path of complicating and deepening the types of analysis, often forgetting to develop forms of presenting research results. The use of diagnostic diagrams allows to present complex multidimensional indicators of enterprise activity in a simple and visual form (cognitive graphics).

A diagnostic chart of the financial condition of the company has been developed using cognitive graphics. For the first time, diagrams of this type were successfully applied by V.A. Lischuk for the diagnosis of cardiovascular system. [6] The structure of integral indicators - the tree of indicators of financial condition is presented in Fig. 3.

There is a minimum set of indicators characterizing vital for any enterprise characteristics of its functioning at the lower level of the three-level hierarchical structure that are

Indicators are divided into 5 groups:

1. management efficiency;

2. solvency;

3. probability of non-bankruptcy;

4. market sustainability;
5. commercial activity.

There are aggregated indicators $\mathrm{Yi}$, defining the strategic goals of an enterprise at the middle level. There is an aggregated indicator of the financial condition of an enterprise, which we denote as " $\mathrm{Z}$ " at the upper level. The choice of indicators of the financial condition of an enterprise at the lower level is determined by the experience and intuition of the developers. Table 2 shows the minimum list of indicators used in this work when constructing a diagnostic chart of the financial condition of an enterprise.

Knowing the weights $w_{i j}$, it is easy to find the contribution of each component of the enterprise's activity to the overall result of its financial condition. It is clear that the greater the "weight", the greater the contribution to the $i$-index of the $j$-component. Moving from the top to the bottom of the tree of indicators, one can "grope" for the so-called "weak link" of the enterprise and establish the cause of the "weakness".

Diagnostics of the upper level allows to assess the position of an enterprise in the group of competitors and the risk of bankruptcy and it is estimated with the indicator - $Z$. The indicator $Z$ reflects the general situation at the enterprise and gives an assessment of the possibility of bankruptcy (bankruptcy risk). The 
Table 2. The list of indicators to construct a chart.

\begin{tabular}{|c|c|}
\hline Key & Explanation \\
\hline & Management efficiency \\
\hline$Y_{1}$ & $\begin{array}{l}\text { Aggregated Governance Score } \\
\left(N_{j}{ }^{1)} ; w_{i j} \text { of weight } ; x_{i j}{ }^{*} \text { - standard }\right)\end{array}$ \\
\hline$x_{11}, \%$ & Return on investment of capital $\left(w_{11}=0,5 ; x_{11}{ }^{*}=4 \%\right)$ \\
\hline$x_{12}, \%$ & Return on sales $\left(w_{12}=0,3 ; x_{12}{ }^{*}=30 \%\right)$ \\
\hline \multirow[t]{2}{*}{$x_{13}, \%$} & Return on equity $\left(w_{13}=0,2 ; x_{13}{ }^{*}=8 \%\right)$ \\
\hline & Solvency \\
\hline$Y_{2}$ & $\begin{array}{c}\text { Solvency Aggregate } \\
\left(N_{j}^{1)} ; w_{i j} \text { of weight; } x_{i j}^{*} \text { - standard }\right)\end{array}$ \\
\hline$x_{21}$ & Critical liquidity ratio $\left(w_{2 l}=0,4 ; x_{2 I}{ }^{*}=0,8\right)$ \\
\hline$x_{22}$ & Current ratio $\left(w_{22}=0,35 ; x_{22}{ }^{*}=2\right)$ \\
\hline \multirow[t]{2}{*}{$x_{23}$} & Absolute liquidity ratio $\left(w_{23}=0,25 ; x_{23}{ }^{*}=0,25\right)$ \\
\hline & Probability of non-bankruptey \\
\hline$Y_{3}$ & Probability of non-bankruptcy $=1--($ Probability of bankruptcy $) ;\left(\mathrm{x}_{31}{ }^{*}-\right.$ norm $)$ \\
\hline \multirow[t]{2}{*}{$x_{31}$} & Z-score $\left(\mathrm{x}_{31}{ }^{*}=3\right)$ \\
\hline & Market sustainability \\
\hline$Y_{4}$ & $\begin{array}{c}\text { Aggregate Market Sustainability Indicator } \\
\left(N_{j}{ }^{1)} ; w_{i j} \text { of weight; } x_{i j}^{*} \text { - standard }\right)\end{array}$ \\
\hline$x_{41}, \%$ & Maneuverability coefficient $\left(w_{41}=0,5 ; x_{41}{ }^{*}=80 \%\right)$ \\
\hline$x_{42}, \%$ & Autonomy coefficient $\left(w_{42}=0,3 ; x_{42}{ }^{*}=80 \%\right)$ \\
\hline \multirow[t]{2}{*}{$x_{43}, \%$} & Dependency ratio $\left(w_{43}=0,2 ; x_{43}{ }^{*}=40 \%\right)$ \\
\hline & Commercial activity \\
\hline$Y_{5}$ & $\begin{array}{c}\text { Aggregated Business Activity } \\
\left(N_{j}{ }^{1)} ; w_{i j} \text { of weight } ; x_{i j}{ }^{*} \text { - standard }\right)\end{array}$ \\
\hline$x_{51}$ & Current assets turnover ratio $\left(w_{5 l}=0,4 ; x_{5 l}{ }^{*}=4\right)$ \\
\hline$x_{52}, \%$ & Wear coefficient $\left(w_{52}=0,3 ; x_{52}{ }^{*}=30 \%\right)$ \\
\hline$x_{53}, \%$ & Receivables level $\left(w_{53}=0,15 ; x_{53}{ }^{*}=30 \%\right)$ \\
\hline$x_{54}, \%$ & $\begin{array}{l}\text { Ratio of stock coverage with own working capital } \\
\left(w_{54}=0,15 ; x_{54}{ }^{*}=60 \%\right)\end{array}$ \\
\hline$Z$ & $\begin{array}{c}\text { Integral indicator of financial condition } \\
\left(W_{1}=0,33 ; W_{2}=0,18 ; W_{3}=0,1\right. \\
\left.W_{4}=0,15 ; W_{5}=0,24\right)\end{array}$ \\
\hline
\end{tabular}

aspiration of $Z$ to zero is an indicator of future bankruptcy.

Diagnostics at the middle level is carried out on a set of 5 indicators: $Y_{1}, \ldots, Y_{5}$. A decrease in the values of the integral indicators $Y_{1}, \ldots, Y_{5}$ warns of an increase in risks associated with the state of the resource base, a decrease in liquidity, a shortfall in profits, etc.

The activity of an enterprise is always associated with risk. Risk is the uncertainty of achieving the goal. The financier is not always able to estimate the probable losses from the decision made - there is simply no complete information for calculating this very probability. There is a need to assess the level of risk with the help of some indicators. The risk level itself can be estimated by solving the classification problem at the average diagnostic level by integral indicators $Y_{1}, \ldots$, $Y_{5}$, having a range of values from 0 to 1 . The maximum level of risk corresponds to the value $Y_{l}$ "0", the minimum - "1".

The diagnostic chart of the financial condition of an enterprise is constructed as follows: the corresponding values of the integral indicators $Y_{1}, \ldots, Y_{5}$ of the tree of indicators of financial condition are plotted on five equidirected coordinate axes.
An enterprise with an "ideal" financial condition on this diagram should be reproduced with a regular pentagon inscribed in a unit circle (this is how the Soviet "Quality Mark" looked). Now we will build a diagram for a virtual enterprise. The values of indicators $x_{i j}$ and the integral indicators $Y_{1}, \ldots, Y_{5}$ depending on them are presented in Table 3. And the diagram itself is presented in Figure 7.

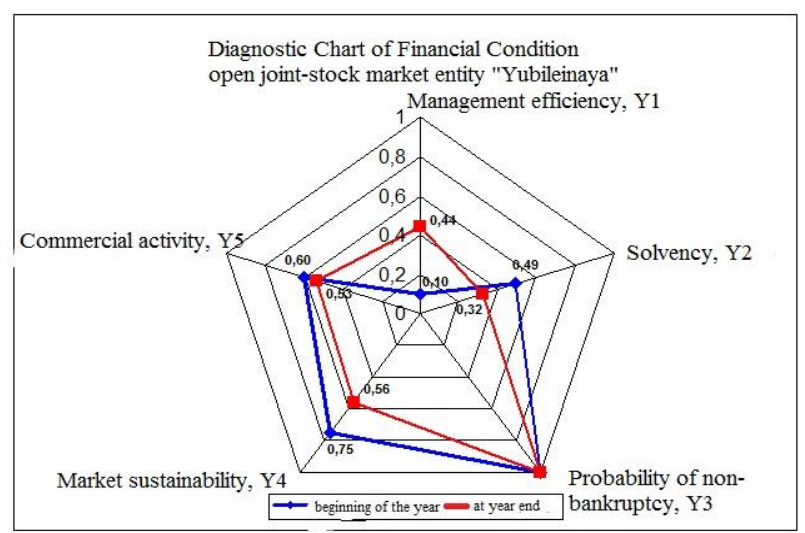

Fig. 4. Diagnostic Chart of Financial Condition. 
Table 3. Values of indicators xij and integral indicators $Y_{l}, \ldots, Y_{5}$ and $\mathrm{Z}$, depending on them.

\begin{tabular}{|c|c|c|c|}
\hline \multirow[t]{2}{*}{ Indicator } & \multicolumn{2}{|c|}{ Meaning } & \multirow[t]{2}{*}{ Change } \\
\hline & $\begin{array}{l}\text { Beginning } \\
\text { of the year }\end{array}$ & $\begin{array}{c}\text { End } \\
\text { of the year }\end{array}$ & \\
\hline \multicolumn{4}{|l|}{ Management efficiency } \\
\hline Integral indicator, $Y_{1}$ & 0,096 & 0,444 & $+0,348$ \\
\hline Return on capital investment, $x_{11}, \%$ & 1,613 & 3,117 & $+1,503$ \\
\hline Return on sales, $x_{12}, \%$ & $-16,273$ & $-7,456$ & $+8,817$ \\
\hline Return on equity, $x_{13}, \%$ & 2,277 & 5,164 & $+2,887$ \\
\hline \multicolumn{4}{|c|}{ Solvency } \\
\hline Integral indicator, $Y_{2}$ & 0,493 & 0,324 & $-0,169$ \\
\hline The critical liquidity ratio, $x_{21}$ & 0,273 & 0,161 & $-0,112$ \\
\hline Current liquidity ratio, $x_{22}$ & 1,985 & 1,378 & $-0,607$ \\
\hline Absolute liquidity ratio, $x_{23}$ & 0,009 & 0,003 & $-0,007$ \\
\hline \multicolumn{4}{|c|}{ Probability of non-bankruptcy } \\
\hline Integral index, $Y_{3}$ & 1 & 1 & 0 \\
\hline Z-score, $x_{31}$ & 17,526 & 3,926 & $-13,6$ \\
\hline \multicolumn{4}{|c|}{ Market sustainability } \\
\hline Integral indicator, $Y_{4}$ & 0,75 & 0,56 & $-0,19$ \\
\hline Maneuverability coefficient, $x_{41}, \%$ & 34,758 & 25,374 & $-9,384$ \\
\hline Autonomy ratio, $x_{42}, \%$ & 70,84 & 60,351 & $-10,489$ \\
\hline Dependency ratio, $x_{43}, \%$ & 41,164 & 65,697 & $+24,533$ \\
\hline \multicolumn{4}{|c|}{ Commercial activity } \\
\hline Integral indicator, $Y_{5}$ & 0,602 & 0,534 & $-0,067$ \\
\hline The turnover rate of current assets, $x_{51}$ & 2,116 & 1,973 & $-0,142$ \\
\hline Wear coefficient, $x_{52}, \%$ & 47,8 & 44,98 & $-2,82$ \\
\hline The level of accounts receivable, $x_{53}, \%$ & 13,168 & 10,9 & $-2,269$ \\
\hline The ratio of stocks of OWC, $x_{54}, \%$ & 54,338 & 32,979 & $-21,359$ \\
\hline Integral indicator, $\mathrm{Z}$ & 0,477 & 0,517 & $+0,04$ \\
\hline
\end{tabular}

You can see that at the end of the year management efficiency is quite low, although it has increased since the beginning of the year in the diagram in Figure 4. The increase in management efficiency is due to the ubiquitous increase in $x_{I i}$ indicators (see Table 3), the negative value of the sales profitability demonstrates losses from main activity of the enterprise.

The aggregate solvency indicator $Y_{2}$ is far from the ideal value. The decrease in the solvency indicator is due to the widespread decline in indicators $x_{I i}$. Liquidity ratios indicate that the enterprise is able to repay shortterm debts, but there are no enough financial resources to ensure the smooth operation of the enterprise. The enterprise is not solvent.

The probability of non-bankruptcy is equal to unity, i.e. the probability of bankruptcy is equal to zero. This is due to the fact that by the end and the beginning of the year the $Z$-score significantly exceeds the value of 3 , although there is a tendency to decrease the Z-score. This suggests a negligible probability of bankruptcy.

The market stability index $Y_{4}$ has also decreased. This was mainly due to a decrease in maneuverability and autonomy ratios. The increase in the coefficient of dependence on the funds raised indicates a decrease in the financial stability of the enterprise.
$Y_{5}$ business activity figures has also fallen. The lower level of debts receivable indicates a poor performance of the company's marketing department. The coefficient of wear is quite large, which indicates the depreciation of fixed assets. In general, the diagram shows that the financial condition of the open joint-stock market entity "Yubileinaya" has deteriorated.

Special attention should be paid to the reliability of the preparation of financial statements. Incorrectly drawn up balance sheet may distort the real financial condition of the enterprise, both for the better and for the worse, which is not permissible in any case.

The essence of the use of diagnostic diagrams is to present complex multidimensional indicators of the financial condition of an enterprise in a simple and visual form.

Today, not only highly qualified specialists are required. Professional information support from analysts is needed. Information, as we know, plays a key role in the enterprise management process. This information makes it possible to obtain data on the enterprise's solvency, its profitability, business activity, sources of formation of financial resources and the effectiveness of their placement, and as a result, an assessment of the effectiveness of the enterprise or its structural units, and 
the assessment should be given not only to the current state, but also to the future.

\section{References}

1. Federal Law of 06.12.2011 No. 402-FZ "On Accounting"

2. Federal Law of October 26, 2002 No. 127-FZ "On Insolvency (Bankruptcy)"

3. Recommendations of the Ministry of Finance of Russia No. PZ-11/2013 "Organization and implementation by an economic entity of internal control of the committed facts of economic life, accounting and compilation of accounting (financial) statements"

4. T.N. Baybikova, On the choice of software cognitive computer visualization, Bulletin of Moscow University of Finance and Law (2017)

5. S.N. Bruskin, Methods and tools for advanced business intelligence for corporate information and analytical systems in the era of digital transformation, Modern information technologies IT education (2016)

6. V.A. Lischuk, Mathematical model of blood circulation, (1999)

7. R.A. Musaeva, L.R. Urazbakhtina, N.A. Serkina, The use of multidimensional analysis tools to assess the credit risk of a bank in order to minimize banking risks, $\mathrm{f}-\mathrm{l}$ Competitiveness in a global world: economics, science, technology, 12(14) (2017)

8. A.N. Savinykh, Analysis and diagnostics of financial and economic activities of the enterprise: a textbook (for bachelor and master degree), 300 (2015)

9. G.V. Savitskaya, Analysis of the economic activity of the enterprise: the textbook, 6 (2017) 